\title{
Construction and expression of a heterologous protein in Lactococcus lactis by using the nisin-controlled gene expression system: the case of the PRRSV ORF6 gene
}

\author{
Z.H. Wang ${ }^{1,2 *}$, Y.L. Wang ${ }^{2 *}$ and X.Y. Zeng ${ }^{2}$ \\ ${ }^{1}$ Department of Animal and Veterinary Science, \\ Chengdu Vocational College of Agricultural Science and Technology, \\ WenJiang, Sichuan, China \\ ${ }^{2}$ Isotope Research Laboratory, College of Life and Basic Sciences, \\ Sichuan Agricultural University, Xin Kang, Ya’an, Sichuan, China \\ *These authors contributed equally to this study. \\ Corresponding author: X.Y. Zeng \\ E-mail: 363150834@qq.com
}

Genet. Mol. Res. 13 (1): 1088-1096 (2014)

Received January 18, 2013

Accepted July 17, 2013

Published February 20, 2014

DOI http://dx.doi.org/10.4238/2014.February.20.10

\begin{abstract}
The porcine reproductive and respiratory syndrome virus (PRRSV) continues to be a threat, exerting significant economic effects on the swine industry worldwide. However, none of the current commercially available vaccines can completely prevent respiratory infection, trans-placental transmission, pig-to-pig transmission of the virus, or maintain immune protection in sows. This study provides information on PRRSV and a review of available options for PRRS control strategies based on its pathogenic characteristics, immune properties, and biological characteristics. In this study, the nisincontrolled expression system of Lactococcus lactis was selected as a vector to express the ORF6 gene of PRRSV. Food-grade recombinant, L. lactis PNZ8149/NZ3900-M/PRRS, which contained the lactose
\end{abstract}


operon, was successfully constructed. The molecular weight of the expressed recombinant protein was approximately $19 \mathrm{kDa}$. Furthermore, the recombinant protein was located on the surface of L. lactis and showed reactogenicity with the antibody against PRRSV. Results of this study are expected to lay a theoretical foundation for development of genetically engineered $L$. lactis mucosal vaccines and to provide information related to its immune activity and adjuvant effects.

Key words: Lactococcus lactis; Nisin-controlled expression system; Porcine reproductive and respiratory syndrome virus (PRRSV); ORF6

\section{INTRODUCTION}

Porcine reproductive and respiratory syndrome (PRRS) continues to be one of the most devastating diseases of swine throughout the world. PRRS is characterized by severe reproductive failure in sows, and by respiratory distress in piglets and growing pigs (Bilodeau et al., 1991). The etiological agent, PRRS virus (PRRSV), is a positive-strand RNA virus belonging to the family Arteriviridae (Meulenberg, 2000). The genome of PRRSV is approximately $15 \mathrm{~kb}$ in length and contains eight open reading frames (ORFs) (Dea et al., 2000). The first two ORFs (ORF1a and ORF1b) encode replicase and polymerase containing proteins. ORFs 2-4 encode three minor membrane-associated glycoproteins (GP), designated as GP2, GP3, and GP4, respectively. ORFs 5-7 encode three major structural proteins of the virion: the envelope GP5, the non-glycosylated membrane protein M, and the nucleocapsid protein $\mathrm{N}$, respectively (Meulenberg et al., 1994, 1995; Snijder and Meulenberg, 1998; Dea et al., 2000). It has been suggested that the $\mathrm{M}$ protein is recognized by porcine $\mathrm{T}$ cells, plays a role in virus infectivity and assembly, and has a highly conservative serotype (Meulenberg et al., 1994; Dea et al., 2000). There are three discontinuous antigen epitopes, EpORF6-ABC, in the M protein of PRRSV, and antibodies against epitopes EpORF6-A and EpORF6-B have neutralizing viral activities (Yang et al., 2000). M proteins have been considered very important to induce cellular immune responses against PRRSV infection and are proposed to be excellent candidate proteins for the design of a PRRS bioengineered vaccine.

Nevertheless, none of the current commercial vaccines is able to completely prevent respiratory infection, trans-placental transmission, pig-to-pig transmission of the virus, or maintain immune protection in sows. We here share information related to PRRSV and review available options for PRRS control strategies based on its pathogenic characteristics, immune properties, and biological characteristics. In this study, the nisin-controlled expression (NICE) system of Lactococcus lactis was selected as the vector of recombinant protein expression to express the ORF6 gene, with the aim of developing genetically engineered L. lactis mucosal vaccines of PRRSV, which are greatly needed to control virus infection (Fynan et al., 1993; Srivastava and Liu, 2003).

The mucosal immune system is an important part of the entire immune network in humans and animals and is structurally and functionally divided into sites for antigen uptake and processing at inductive sites. The mucosal immune system plays an important role in infection resistance. First, mucosal secretory immunoglobulin A can form a barrier to pathogens at the mucosal surface by preventing the initial attachment of the pathogen and its infiltration 
of surface layers, or by binding to and neutralizing toxins produced by the pathogen, which is the first line of defending infection. Second, the mucosal immune system has a common mucosal immune mechanism, which maintains a consistent systemic mucosal immunity status. However, the mucosal immune system must also be capable of inducing effective cellmediated and antibody-mediated immune responses toward selected antigens (Holmgren and Czerkinsky, 2005). Together, this information indicates that the mucosal immune system provides a potential management strategy for the development of new technologies in the field of epidemics prevention.

L. lactis is a homofermentative bacterium. Its primary function is involved in rapid lactic acid production from lactose. Functional characteristics that have been extensively studied in L. lactis include its carbon metabolism, extracellular and intracellular proteolytic system, production of antibiotic substances, and its interaction with and resistance to bacteriophages. At present, genomic information of at least 5 strains of L. lactis is publicly available. This wealth of knowledge and experience has led to the broad use of L. lactis in several fields of biotechnology, e.g., the expression of bacterial and viral antigens for safe vaccination via mucosal immunization, the production of human cytokines and other therapeutic agents for in situ treatments, as a cell factory for the production of specific compounds, and pilot studies of pharmaceutical products (Kleerebezem and Hugenholtz, 2003; Kunji et al., 2005). The availability of an easy-to-operate and strictly controlled gene expression system (NICE) has been crucial for the development of many of these applications. Therefore, research programs focused on lactic acid bacteria consumed as a mucosal vaccine are increasingly prevalent.

To develop a food-grade expression system for an oral/nasal vaccine against PRRSV infection, we extracted the total RNA of PRRSV, cloned the ORF6 gene by reverse transcription-polymerase chain reaction (RT-PCR), and sequenced the complete gene. Then, the ORF6 gene was inserted into the NICE system NZ3900/PNZ8149, which contained the food-grade selection marker lacF. We named the recombination expression system NZ3900/ PNZ8149-ORF6. Sodium dodecyl sulfate-polyacrylamide gel electrophoresis (SDS-PAGE) and an immunofluorescence assay (IFA) revealed that the M protein was highly expressed by L. lactis and had favorable immunogenicity.

\section{MATERIAL AND METHODS}

\section{Virus}

The PRRSV CH-1R strain (PRRSV CH-1R) was isolated from the lungs of Sichuan pigs at the acute stage of PRRSV infection, which was identified as a high-virulent North American-type isolate. The virus was propagated and tiered in MARC-145 cells. MARC-145 cells were grown and maintained in Dulbecco's modified Eagle's medium supplemented with $10 \%$ heated-inactivated fetal bovine serum, $100 \mu \mathrm{g} / \mathrm{mL}$ streptomycin, and $100 \mathrm{IU} / \mathrm{mL}$ penicillin at $37^{\circ} \mathrm{C}$ and $5 \% \mathrm{CO}_{2}$.

\section{Bacterial strains and vector}

The L. lactis NZ3900 standard strain was selected for food-grade selection based upon its ability to grow on lactose. This strain is a progeny of NZ3000, in which the lactose operon 
that is generally present on plasmids has been integrated into the chromosome and the lacF gene has been deleted. Deletion of the lacF gene makes this strain unable to grow on lactose unless lacF is provided in a plasmid.

PNZ8149 was used as the broad host range vector, and lacF was used for food-grade selection for growth on lactose. The vector contains a nisA promoter followed by an NcoI site for translational fusions at the start codon (ATG) and a terminator after the modulation coding scheme. Sequence adaptation for cloning in $\mathrm{Nco}$ I can result in a change in the second amino acid of a protein.

\section{Amplification and sequence identification of ORF6 genes}

To amplify the PRRSV ORF6 genes, one pair of PCR primers (Table 1) was designed based on sequences published in GenBank (accession No. Eu025139), and the restriction endonuclease sites of $\mathrm{SacI}$ and $\mathrm{NcoI}$ were added to both ends of the modified ORF6 protein gene based on the structure of PNZ8149. The ORF6 structural protein gene of PRRSV containing the restriction endonuclease sites of $\mathrm{SacI}$ and $\mathrm{NcoI}$ was amplified by RT-PCR and purified using the Agarose Gel DNA Purification Kit (TaKaRa Biotechnology Co., Ltd., Dalian, China). The purified specific fragment was cloned into a PMD19-T vector and identified by specific restriction enzyme digesting and sequencing.

\section{Construction of NZ3900/PNZ8149-ORF6}

The L. lactis NZ3900 containing the plasmid PNZ8149 (PNZ8149/NZ3900) was inoculated in M17 medium, containing $0.5 \%$ lactose as the carbon source and a plasmid selection agent. The basic fermentation medium contained $0.5 \%$ tryptone, $0.5 \%$ yeast extract (Biospringer, Maisons-Alfort, France), $0.5 \%$ soy peptone (Merck, VWR International, Amsterdam, The Netherlands), $0.5 \%$ beef extract, $0.05 \%$ L-ascorbic acid, $0.025 \%$ magnesium sulfate, $17.1 \%$ sucrose, $2.5 \%$ glycine, and $1.9 \% \beta$-glycerophosphate. PNZ8149/NZ3900 was cultured for $12-16 \mathrm{~h}$ at $30^{\circ} \mathrm{C}$ (de Ruyter et al., 1997). The cell precipitate was collected by centrifugation, and plasmid DNA of PNZ8149 was isolated from L. lactis NZ3900 with a modified plasmid small amount kit (Wan et al., 2010). The plasmid ORF6 and the plasmid PNZ8149 were digested with the restriction endonucleases SacI and NcoI, respectively. The gene fragment of interest, ORF6, was inserted into the PNZ8149 vector, which was named PNZ8149-ORF6.

Electroporation was used to introduce recombinant plasmids (PNZ8149-ORF6) into L. lactis NZ3900. Electro-competent NZ3900 cells were prepared by sub-inoculating an overnight culture of L. lactis NZ3900 in M17 medium, supplemented with $0.5 \mathrm{M}$ sucrose and $2.5 \%$ glycine, for $18-20 \mathrm{~h}$ at $30^{\circ} \mathrm{C}$. Cells were collected by centrifugation and prepared as described by Holo and Nes (Wan et al., 2010). One-hundred microliters of the cell suspension was placed in a pre-chilled electroporation cuvette with $25 \mu \mathrm{L}$ DNA (reconstituted in TE-buffer). The cuvette was kept on ice during electroporation, which was run at a phase of $2.5 \mathrm{kV}$ and

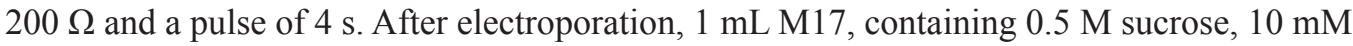
$\mathrm{CaCl}_{2}$, and $10 \mathrm{mM} \mathrm{MgCl}_{2}$, was added to the cuvette. The cuvette was kept on ice for $5 \mathrm{~min}$ and then was incubated at $30^{\circ} \mathrm{C}$ for $2 \mathrm{~h}$. Finally, 10,100 , and $900 \mu \mathrm{L}$ cells were plated on Ellice medium with lactose and Bromocresol Purple and incubated for $1-2$ days at $30^{\circ} \mathrm{C}$. 


\section{Nisin induction of ORF6 gene expression in L. lactis}

Nisin is a 34-amino acid anti-microbial peptide (lantibiotic). Nisin powder $(0.04 \%)$ was dissolved in $0.05 \%$ acetic acid and precipitated proteins were removed by centrifugation. Nisin was added for induction as indicated in the Results section.

The single colony was sub-cultured in the basic fermentation medium $(20 \mathrm{~g} / \mathrm{L}$ yeast extract, $25 \mathrm{~g} / \mathrm{L}$ tryptone, $1 \mathrm{mM} \mathrm{MgSO}, 0.1 \mathrm{mM} \mathrm{MnSO}_{4}, 0.5 \%$ lactose, and $0.1 \mathrm{~g} / \mathrm{L} \mathrm{Na}_{2} \mathrm{HPO}_{4}$, $\mathrm{pH}=7.0$ ) before inoculation, and the $3000-\mathrm{L}$ basic fermentation medium was used for culture. The cell density was measured in samples taken at regular intervals by determining the absorbance at $600 \mathrm{~nm}$ with a path length of $1 \mathrm{~cm}\left[\mathrm{OD}_{600}\right]$, at which point a final concentration of $10 \mathrm{ng} / \mathrm{mL}$ nisin was added. Meanwhile, the other $10-\mathrm{mL}$ culture was maintained as a negative control. Following the induction, the culture was shocked for $6 \mathrm{~h}$ at $30^{\circ} \mathrm{C}$ before harvested. Fermentations were terminated by rapid cooling to $4^{\circ} \mathrm{C}$ and were stored for approximately 12 $\mathrm{h}$ at this temperature before further processing. Cells were collected by centrifugation, and protein production was routinely monitored using SDS-PAGE (Sambrook and Russell, 2001).

\section{Indirect IFA}

Cells were prepared as described above, washed with phosphate-buffered saline (PBS), and fixed with cold methanol for $10 \mathrm{~min}$. Cells were blocked in $1 \%$ bovine serum albumin in PBS for $30 \mathrm{~min}$ at room temperature. The first antibodies (rabbit anti-PRRSV M antibody) were incubated with cells for $2 \mathrm{~h}$ at a dilution of 1:50. After washing with PBS three times, cells were incubated with secondary antibody (fluorescein isothiocyanate-labeled goat anti-rabbit) at a dilution of 1:100 for another $1 \mathrm{~h}$ at room temperature. Cells were again washed in PBS three times, and observations were conducted with a fluorescent microscope.

\section{RESULTS}

\section{Identification of recombinant plasmids PNZ8149-ORF6}

To identify whether the ORF6 gene was inserted into PNZ8149, PCR screening was performed on genomic DNA of PNZ8149-ORF6 with primers (Table 1). Results showed that the expected DNA band of the ORF6 gene had been amplified; the PCR product was approximately 538 bp in length, representing the ORF gene ( $525 \mathrm{bp}$ ) plus the 13-bp restriction sites. This result was double-checked by double-digestion of the specific restriction endonucleases $\mathrm{SacI}$ and NcoI. The expected DNA band of the ORF6 gene was obtained, and the sequence was simultaneously detected (data not shown). These results indicated that the target genes had been successfully recombined into PNZ8149 according to the previous design (Figure 1).

\begin{tabular}{|c|c|c|}
\hline Amplified gene & Primers $\left(5^{\prime}-3^{\prime}\right)$ & Annealing temperature $\left({ }^{\circ} \mathrm{C}\right)$ \\
\hline PRRSV-ORF6 (525 bp) & $\begin{array}{l}\text { P1: 5'-TCA } \frac{C C A T G G G G T C G T C C C T A G A C-3 '}{N c o I} \\
\text { P2: 5'-CGGAGCTCTTATTTGGCATATTTGACAAG-3' } \\
\text { SacI }\end{array}$ & 55 \\
\hline
\end{tabular}




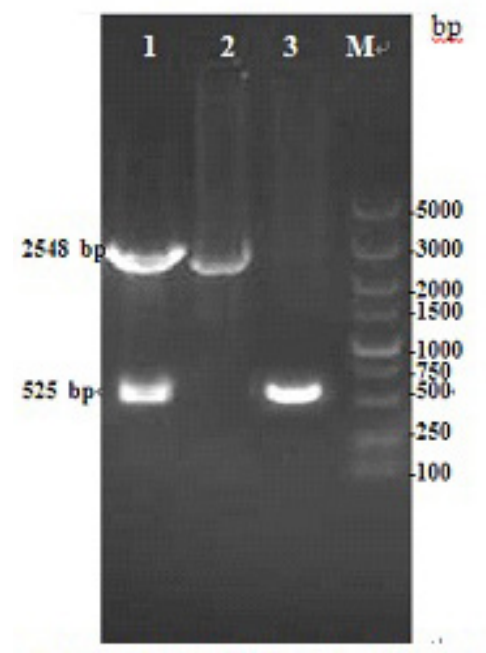

Figure 1. Identification of PNZ8149/NZ3900-M/PRRS digested by restriction endonuclease and PCR. Lane M = DNA marker (DL5000); lane 1 = PNZ8149/NZ3900-M/PRRS digested by SacI and NcoN; lane 2 = PNZ8149/ NZ3900 digested by SacI and NcoN; lane 3 = PCR identification of PNZ8149/NZ3900-M/PRRS.

\section{Induced expression of the recombinant $L$. lactis}

The recombinant protein was detected by SDS-PAGE and IFA after the bacteria were induced with $10 \mathrm{ng} / \mathrm{mL}$ nisin. Results indicated that the molecular weight of the expressed recombinant protein was approximately $19 \mathrm{kDa}$ (Figure 2). Moreover, the protein was secreted and located on the surface of the bacteria, and the protein maintained reactogenicity with the antibody against PRRSV as expected (Figure 3).

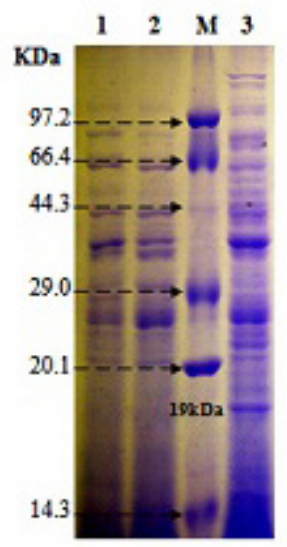

Figure 2. SDS-PAGE analysis of the recombinant $\mathrm{M}$ protein. Lane $M=$ protein marker; lane $1=$ uninduced PNZ8149/NZ3900-M/PRRS; lane 2 = induced PNZ8149/NZ3900; lane 3 = induced PNZ8149/NZ3900-M/PRRS for $6 \mathrm{~h}$. 

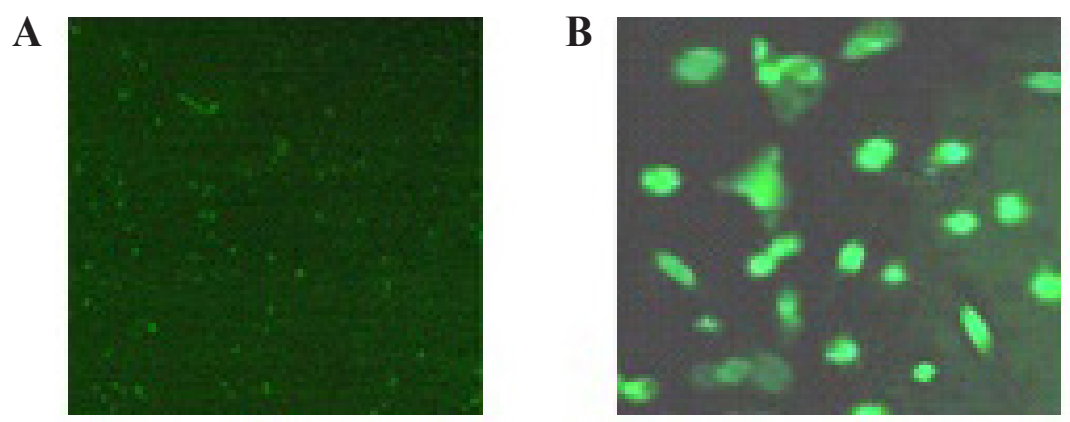

Figure 3. Indirect immunofluorescence detection of the expressed proteins in the NZ3900 bacteria. A. Induced PNZ8149/NZ3900. B. Induced PNZ8149/NZ3900-M/PRRS.

\section{DISCUSSION}

PRRS is the most globally significant infectious disease of swine. Recently, another highly pathogenic swine disease, designated as porcine high fever disease (PHFD), was identified, which is caused by the atypical NA PRRSV containing two discontinuous sequence deletions in the Nsp2 gene. PHFD continues to pose a problem in China and Vietnam (Wu et al., 2009), but not in Thailand (the Chulalongkorn University, Veterinary Diagnostic Laboratory, unpublished data). Control of PRRSV has proven to be difficult, even with vaccination. Therefore, protection against PRRSV infection remains a matter of primary importance for swine producers. In general, live animals, air spread, and semen are considered the primary sources of PRRSV transmission (Torremorell et al., 2004). Mucosal immunity plays a major role in the prevention of infectious diseases, and the produced PRRSV subunit vaccines are able to confer a certain level of protection (Osorio, 2010). In this study, we constructed an oral/nasal vaccine against PRRSV infection. As a highly hydrophobic protein, the M protein could be expressed in several vectors, including Pichia pastoris (Qian et al., 2003). Membrane proteins carry out a wide range of functions in vital processes, and are therefore the most important group of proteins with respect to drug targets. The PRRSV M protein is the most conserved structural protein between European and North American isolates. It is highly antigenic; the detectable antibody response can be elicited as early as 10 days after infection. Therefore, the recombinant protein is a useful antigen for subunit vaccine and serum tests.

L. lactis has been developed as an excellent tool for the expression and study of integral membrane proteins of both prokaryotes and eukaryotes (Kunji et al., 2003; Monné et al., 2009). Furthermore, L. lactis are increasingly used as oral/nasal delivery vehicles for therapeutic and prophylactic proteins (Mierau et al., 2005a,b; Le Loir et al., 2005; Zhou et al., 2006). It can elicit more effective immunological responses and reduce the risk of eliciting immunologic tolerance compared with persistent strains. In addition, L. lactis is so small that it can be taken up easily by cells and can contribute to the immunogenic adjuvant activity as LTB and CpG oligodeoxynucleotide (CpG ODN) (Ouwehand et al., 2002; Ahmed, 2003). L. lactis is a Gram-positive bacterium, which presents several advantages over Escherichia coli. One of its major advantages is that it does not form inclusion bodies. L. lactis has the potential for high expression levels, efficient secretion, expression of membrane proteins, and over-expression of homologous and heterologous genes for functional studies and to obtain large quantities of 
specific gene products. In addition, it is less endogenous and contains no exogenous proteases, has a food grade expression system, its tightly controlled gene expression allows production of toxic proteins, has simple fermentation, and scale-up and downstream processing (Ravn et al., 2003; Martínez-Cuesta et al., 2005; Novotny et al., 2005; Wells and Mercenier, 2008).

The present study describes construction of the first real and complete safety expression system designed to express the antigen protein of PRRSV. We used the L. lactis NZ3900 as the host strain and a food-grade expression system to express the recombinant $\mathrm{M}$ protein of PRRSV. The ORF6 gene was cloned from the PRRSV CH-1R strain, and was then inserted downstream of the NisA promoter on the plasmid PNZ8149. The expression plasmid PNZ8149 was electro-transformed into NZ3900 cells. Then, the M protein-expressing gene was induced by the addition of sub-inhibitory amounts of nisin to the culture medium. Furthermore, we demonstrated that the recombinant protein was highly expressed and had favorable immunogenicity. This study provides new possibilities for the prevention of PRRSV infectious diseases by mucosal immunity. Other advantages of this method are that L. lactis does not produce inclusion bodies or endotoxins and does not produce spores and extracellular proteins (Mierau et al., 2005a). Furthermore, it is very convenient to separate and purify the M protein, and it is safe for experimental studies and industrial production to the PRRSV infection.

\section{CONCLUSION}

In this study, we successfully constructed a food-grade recombinant $L$. lactis expressing the PRRSV ORF6 gene and containing the lactose operon. The molecular weight of the expressed recombinant protein was approximately $19 \mathrm{kDa}$. Furthermore, the recombinant protein was located on the surface of the bacteria and had reactogenicity with antibody against PRRSV. This study is expected to provide a theoretical foundation for development of genetically engineered L. lactis mucosal vaccines in order to evaluate its immune activity and adjuvant effects.

\section{REFERENCES}

Ahmed FE (2003). Genetically modified probiotics in foods. Trends Biotechnol. 21: 491-497.

Bilodeau R, Dea S, Sauvageau RA and Martineau GP (1991). Porcine reproductive and respiratory syndrome in Quebec. Vet. Rec. 129: 102-103.

de Ruyter PG, Kuipers OP, Meijer WC and de Vos WM (1997). Food-grade controlled lysis of Lactococcus lactis for accelerated cheese ripening. Nat. Biotechnol. 15: 976-979.

Dea S, Gagnon CA, Mardassi H, Pirzadeh B, et al. (2000). Current knowledge on the structural proteins of porcine reproductive and respiratory syndrome (PRRS) virus: comparison of the North American and European isolates. Arch. Virol. 145: 659-688.

Fynan EF, Webster RG, Fuller DH, Haynes JR, et al. (1993). DNA vaccines: protective immunizations by parenteral, mucosal, and gene-gun inoculations. Proc. Natl. Acad. Sci. U. S. A. 90: 11478-11482.

Holmgren J and Czerkinsky C (2005). Mucosal immunity and vaccines. Nat. Med. 11: S45-S53.

Kleerebezem M and Hugenholtz J (2003). Metabolic pathway engineering in lactic acid bacteria. Curr. Opin. Biotechnol. 14: 232-237.

Kunji ER, Slotboom DJ and Poolman B (2003). Lactococcus lactis as host for overproduction of functional membrane proteins. Biochim. Biophys. Acta 1610: 97-108.

Kunji ER, Chan KW, Slotboom DJ, Floyd S, et al. (2005). Eukaryotic membrane protein overproduction in Lactococcus lactis. Curr. Opin. Biotechnol. 16: 546-551.

Le Loir Y, Azevedo V, Oliveira SC, Freitas DA, et al. (2005). Protein secretion in Lactococcus lactis: an efficient way to increase the overall heterologous protein production. Microb. Cell Fact. 4: 2. 
Martínez-Cuesta MC, Gasson MJ and Narbad A (2005). Heterologous expression of the plant coumarate: CoA ligase in Lactococcus lactis. Lett. Appl. Microbiol. 40: 44-49.

Meulenberg JJ (2000). PRRSV, the virus. Vet. Res. 31: 11-21.

Meulenberg JJ, Hulst MM, de Meijer EJ, Moonen PL, et al. (1994). Lelystad virus belongs to a new virus family, comprising lactate dehydrogenase-elevating virus, equine arteritis virus, and simian hemorrhagic fever virus. Arch. Virol. (Suppl 9): 441-448.

Meulenberg JJ, Petersen-den BA, de Kluyver EP, Moormann RJ, et al. (1995). Characterization of proteins encoded by ORFs 2 to 7 of Lelystad virus. Virology 206: 155-163.

Mierau I, Leij P, van Swan I, Blommestein B, et al. (2005a). Industrial-scale production and purification of a heterologous protein in Lactococcus lactis using the nisin-controlled gene expression system NICE: the case of lysostaphin. Microb. Cell Fact. 4: 15.

Mierau I, Olieman K, Mond J and Smid EJ (2005b). Optimization of the Lactococcus lactis nisin-controlled gene expression system NICE for industrial applications. Microb. Cell Fact. 4: 16.

Monné M, Chan KW, Slotboom DJ and Kunji ER (2005). Functional expression of eukaryotic membrane proteins in Lactococcus lactis. Protein Sci. 14: 3048-3056.

Novotny R, Scheberl A, Giry-Laterriere M, Messner P, et al. (2005). Gene cloning, functional expression and secretion of the S-layer protein SgsE from Geobacillus stearothermophilus NRS 2004/3a in Lactococcus lactis. FEMS Microbiol. Lett. 242: 27-35.

Osorio F (2010). PRRSV infections: a world-wide update (2010). Acta Sci. Vet. 38 (Suppl 1): s269-s275.

Ouwehand A, Isolauri E and Salminen S (2002). The role of the intestinal microflora for the development of the immune system in early childhood. Eur. J. Nutr. 41 (Suppl 1): I32-I37.

Qian P, Li X, Tong G and Chen H (2003). High-level expression of the ORF6 gene of porcine reproductive and respiratory syndrome virus (PRRSV) in Pichia pastoris. Virus Genes 27: 189-196.

Ravn P, Arnau J, Madsen SM, Vrang A, et al. (2003). Optimization of signal peptide SP310 for heterologous protein production in Lactococcus lactis. Microbiology 149: 2193-2201.

Sambrook J and Russell DW (2001). Molecular Cloning: A Laboratory Manual. Cshl Press, New York.

Snijder EJ and Meulenberg JJ (1998). The molecular biology of arteriviruses. J. Gen. Virol. 79: 961-979.

Srivastava IK and Liu MA (2003). Gene vaccines. Ann. Intern. Med. 138: 550-559.

Torremorell M, Geiger J, Thompson B and Christianson W (2004). Evaluation of PRRSV outbreaks in negative herds. In Ipvs 1: 103.

Wan Q, Cao J and Wu XQ (2010). Optimization of plasmid extraction method from lactic acid bacteria [J]. China Biotechnol. 30: 94-99.

Wells JM and Mercenier A (2008). Mucosal delivery of therapeutic and prophylactic molecules using lactic acid bacteria. Nat. Rev. Microbiol. 6: 349-362.

Wu J, Li J, Tian F, Ren S, et al. (2009). Genetic variation and pathogenicity of highly virulent porcine reproductive and respiratory syndrome virus emerging in China. Arch. Virol. 54: 1589-1597.

Yang L, Frey ML, Yoon KJ, Zimmerman JJ, et al. (2000). Categorization of North American porcine reproductive and respiratory syndrome viruses: epitopic profiles of the N, M, GP5 and GP3 proteins and susceptibility to neutralization. Arch. Virol. 145: 1599-1619.

Zhou XX, Li WF, Ma GX and Pan YJ (2006). The nisin-controlled gene expression system: construction, application and improvements. Biotechnol. Adv. 24: 285-295. 